\title{
THỰC TRẠNG DỰ BÁO NHU CẦU SỬ DỤNG ĐÂT VÀ ÚNG DỤNG CÔNG NGHỆ TRONG DỬ BÁO NHU CẦU SỬ DỤNG ĐẤT
}

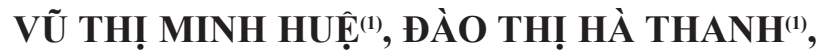 \\ VŨ THI HỒNG(1), NGUYẼ̃N VĂN HẬU ${ }^{(2)}$ \\ (I)Viện Nghiên cứu quản lý đất đai, Tổng cục quản lý đất đai \\ ${ }^{(2)}$ Cục Quy hoạch đất đai, Tổng cục quản lý đất đai
}

\section{Tóm tắt:}

Bài báo này giới thiệu thực trạng dụ báo nhu cầu sủ dụng đất và khả năng ứng dụng công nghệ trong dư báo nhu cầu sử dụng đất tù đó đề xuất một số vấn đề cần đổi mới góp phần nâng cao chất luọng dụ báo, nâng cao tính định hương, tính dụ báo của quy hoạch sủ dụng đất nhằm đảm bảo tính hiệu quả, tính khả thi của phương án quy hoạch.

\section{1. Đặt vấn đề}

Dự báo nhu cầu sử dụng đất đóng vai trò quan trọng trong việc định hướng, lập các chiến lược, quy hoạch, kế hoạch sử dụng đất nói riêng và công tác quản lí đất đai nói chung, góp phần sử dụng đất một cách có hiệu quả, tiết kiệm, tránh lãng phí. Kết quả dự báo là xuất phát điểm, luận chứng trong quá trình xây dựng quy hoạch, kế hoạch sử dụng tài nguyên đất đai. Tuy nhiên, việc dự báo nhu cầu sử dụng đất còn một số hạn chế về phương pháp dự báo; chất lượng dự báo; khả năng ứng dụng công nghệ trong dự báo nhu cầu sử dụng đất... Do đó việc nghiên cứu thực trạng dự báo nhu cầu sử dụng đất và khả năng ứng dụng công nghệ trong dự báo nhu cầu sử dụng đất là hết sức cần thiết nhằm đánh giá những khó khăn, hạn chế từ đó đưa ra những vấn đề cần đổi mới khi dự báo nhu cầu sử dụng đất và ứng dụng công nghệ trong dự báo nhu cầu sử dụng đất.

\section{Thực trạng công tác dự báo nhu cầu sử} dụng đất trong xây dụng phương án quy hoạch sử dụng đất

Việc dự báo nhu cầu sử dụng đất trong xây dựng phương án quy hoạch sử dụng đất được thực hiện qua từng giai đoạn tùy thuộc vào điều kiện, hoàn cảnh, nhiệm vụ phát triển kinh tế - xã hội; các văn bản pháp luật và các tài liệu hướng dẫn liên quan đến công tác lập, thực hiện quy hoạch sử dụng đất tại các giai đoạn đó.

Giai đoạn tì̀ khi có Luật Đất đai 1988 đến trước khi có Luật Đất đai 1993: Thời gian này cũng là thời gian đầu nước ta thực hiện công cuộc đổi mới. Ở nông thôn đã diễn ra những thay đổi sâu sắc cùng với việc giảm bớt vai trò của hợp tác xã, tăng quyền tự chủ trong sản xuất cho hộ nông dân và thực thi các chính sách đổi mới khác, công tác quy hoạch đất đai cấp xã cần được thực hiện nhanh nhằm giải quyết một số vấn đề cấp thiết như: Quy hoạch giao đất (bao gồm cả đất đang sản xuất và đất mở rộng diện tích) để làm căn cứ cho việc giao đất, cấp giấy chứng nhận quyền sử dụng đất; quy hoạch giãn dân (làm căn cứ để giao đất ở hộ nông dân).

Dự báo nhu cầu sử dụng đất theo mục đích sử dụng: chủ yếu tập trung vào nhu cầu các loại đất ở, đất khu dân cư, đất sản xuất nông nghiệp và đất chưa sử dụng có thể mở rộng diện tích vào mục đích sản xuất nông, lâm nghiệp (theo phân loại đất của Luật Đất đai 1988).

Phương pháp dự báo: Đối với đất ở và đất khu dân cư dựa trên dự báo dân số, quy mô hộ giảm dần, số hộ tồn đọng, số nam giới ở độ tuổi kết hôn, tỷ lệ lập gia đình, số phụ nữ nhỡ thì, diện chính sách, phong tục chung sống các thế hệ, thừa kế ở địa phương (để xác định tỷ lệ tách 
hộ)...; Đối với đất sản xuất nông nghiệp, đất chưa sử dụng chủ yếu dựa trên kinh nghiệm sản xuất của bà con địa phương để xác định khả năng chuyển đổi cơ cấu cây trồng, khai hoang mở rộng diện tích sản xuất nông nghiệp, trồng rừng phủ xanh đất trống đồi trọc.

Giai đoạn tù khi có Luật Đất đai 1993 đến truớc khi có Luật Đất đai 2003: Sau vài năm chuyển sang nền kinh tế thị trường, Đảng và Nhà nước đã nhận thức rõ vai trò quan trọng của công tác quy hoạch nói chung, quy hoạch sử dụng đất đai nói riêng. Hệ thống văn bản pháp luật cho công tác quy hoạch sử dụng đất đai đã nhiều hơn, đầy đủ hơn và đồng bộ hơn giai đoạn trước. Công tác tổ chức triển khai lập quy hoạch, kế hoạch sử dụng đất đã được các cấp các ngành quan tâm, được triển khai ở cả bốn cấp cả nước (quốc gia), tỉnh, huyện, xã trên khắp các địa phương trong cả nước.

Dự báo nhu cầu sử dụng đất theo mục đích sử dụng: là căn cứ quan trọng để xác định nhu cầu sử dụng đất của các ngành, các lĩnh vực đến năm định hình quy hoạch, được đề cập đầy đủ và toàn diện hơn so với kỳ trước, được tính cho tất cả các loại đất phân theo mục đích sử dụng (đất nông nghiệp, đất lâm nghiệp, đất chuyên dùng, đất ở, đất chưa sử dụng); phân theo 6 loại đất (đất nông nghiệp, đất lâm nghiệp, đất chuyên dùng, đất chưa sử dụng nằm ngoài khu dân cư và đất khu dân cư nông thôn, đất đô thị) và được xác định cho tất cả các cấp quy hoạch. Việc phân loại đất căn cứ theo Luật Đất đai 1993 và văn bản hướng dẫn về quy hoạch giai đoạn này.

Phương pháp dự báo: chủ yếu được xác định dựa trên những chỉ dẫn về nội dung và phương pháp lập quy hoạch sử dụng đất đai trong tập tài liệu hướng dẫn của Tổng cục Địa chính tại Hội nghị tập huấn công tác quy hoạch, kế hoạch sử dụng đất đai (Đà Nẵng 22 - 26/10/1998), cụ thể một số chỉ dẫn như: Đất cây hàng năm: được dự báo căn cứ vào diện tích, năng suất, sản lượng qua các năm và mục tiêu cần đạt quy hoạch cần đạt được của các chủng loại nông sản; Đất cây lâu năm và cây ăn quả được dự báo căn cứ vào đánh giá thích nghi đất đai và số diện tích thích nghi với cây lâu năm nhưng chưa được khai thác sử dụng; nhu cầu các loại sản phẩm; năng suất dự báo; Đất nuôi trồng thủy sản được xác định căn cứ vào điều kiện tự nhiên và diện tích mặt nước thích hợp với việc nuôi trồng thủy sản (theo kết quả của đánh giá thích nghi đất đai); Đất lâm nghiệp căn cứ tính thích nghi và khả năng tận dụng các loại đất hiện chưa được sử dụng; yêu cầu phát triển KT- XH (nhu cầu về lâm sản) kết hợp với bảo vệ đất đai và môi trường sinh thái; Đất phát triển đô thị căn cứ vào quy mô dân số thành thị, định mức sử dụng đất đến năm định hình quy hoạch; Đất ở nông thôn được xác định trên cơ sở số hộ có nhu cầu đất ở mới và định mức giao đất ở mới theo điều kiện của địa phương; Đất phát triển công nghiệp, đất giao thông, đất thủy lợi căn cứ vào dự báo của quy hoạch ngành, quy hoạch sử dụng đất có nhiệm vụ kiểm tra quy định, bổ sung, điều hòa và cân đối chung quỹ đất cho phát triển công nghiệp, đất giao thông, đất thủy lợi.

Ngoài một số chỉ dẫn về dự báo nêu trên, các phương pháp toán kinh tế, dự báo và ứng dụng công nghệ tin học trong quy hoạch sử dụng đất ở thời kỳ này cũng đã được nêu ra, nhưng chỉ dừng ở mức độ nghiên cứu hoặc có ứng dụng ở phạm vi nhỏ lẻ đối với việc lập quy hoạch sử dụng đất.

Thực tế cho thấy, khi triển khai lập quy hoạch ở các địa phương, các nhà lập quy hoạch còn sử dụng các phương pháp như: các ngành, các lĩnh vực theo yêu cầu của quy hoạch sử dụng đất tự dự báo nhu cầu sử dụng đất của ngành, lĩnh vực mình (căn cứ vào quy hoạch ngành hoặc tự xác định trong điều kiện chưa có quy hoạch ngành) và đăng ký nhu cầu sử dụng đất đưa vào quy hoạch; phương pháp định mức đối với các loại đất xây dựng (trong đất chuyên dùng) sử dụng vào các mục đích văn hóa, giáo dục, thể dục thể thao, y tế, thương mại... trên cơ sở rà soát hiện trạng sử dụng đất cho các mục đích này và mục tiêu cần có đến năm định hình quy hoạch, định 
mức sử dụng đất của các loại công trình. Khi nghiên cứu các tài liệu quy hoạch sử dụng đất ở giai đoạn này, đặc biệt là các tài liệu do đơn vị Viện Điều tra Quy hoạch Đất đai tư vấn lập tại Quảng Nam - Đà Nẵng, Long An, Quảng Trị, Bình Định, Đồng Nai... việc dự báo nhu cầu sử dụng đất được quan tâm và áp dụng thông qua các bảng biểu tính toán đính kèm trong báo cáo bên cạnh hệ thống bảng biểu số liệu đất đai theo quy định và các dẫn dắt, lập luận thể hiện trong báo cáo.

Các giai đoạn tù năm 2003 đến nay (thực hiện Luật Đất đai 2003, 2013): Công tác lập quy hoạch, kế hoạch sử dụng đất qua các thời kỳ được thực hiện theo các quy định cụ thể sau:

- Giai đoạn điều chỉnh quy hoạch sử dụng đất đến năm 2010, kế hoạch sử dụng đất 5 năm kỳ cuối 2006 - 2010 thực hiện theo quy định của Luật Đất đai 2003, Nghị định số 181/2004/NĐCP, Thông tư số 30/2004/TT-BTNMT.

- Giai đoạn lập quy hoạch sử dụng đất sử dụng đất đến năm 2020, kế hoạch sử dụng đất kỳ đầu 2011 - 2015, thực hiện theo quy định của Luật Đất đai 2003, Nghị định số 69/2009/NĐCP, Thông tư số 19/2009/TT-BTNMT.

- Giai đoạn điều chỉnh quy hoạch sử dụng đất đến năm 2020, kế hoạch sử dụng đất 5 năm kỳ cuối 2016 - 2020 thực hiện theo quy định của Luật Đất đai 2013, Nghị định số 143/2014/NĐCP, Thông tư số 29/2014/TT-BTNMT.

Dự báo NCSDĐ theo mục đích sử dụng: Kế thừa các nghiên cứu cơ sở lý luận, cơ sở thực tiễn, phương pháp lập quy hoạch sử dụng đất và các quy định của giai đoạn trước, các giai đoạn thực hiện Luật Đất đai 2003, 2013 đã bổ sung và luật hóa những nguyên tắc, căn cứ lập quy hoạch, kế hoạch sử dụng đất làm cơ sở cho việc dự báo nhu cầu sử dụng đất. Nhưng việc nghiên cứu hoàn thiện các phương pháp dự báo nhu cầu sử dụng đất để triển khai lập quy hoạch, kế hoạch sử dụng đất trên diện rộng chưa được quan tâm đúng mức.
Về cơ bản, việc dự báo nhu cầu sử dụng đất vẫn sử dụng các phương pháp như giai đoạn từ khi có Luật Đất đai 1993 đến trước khi có Luật Đất đai 2003. Tuy nhiên, điểm khác biệt ở các giai đoạn này là văn bản quy định, hướng dẫn lập quy hoạch đề cao vai trò các ngành, các lĩnh vực và đơn vị hành chính cấp dưới trong việc tự dự báo nhu cầu sử dụng đất của ngành, lĩnh vực, cấp mình. Nhiệm vụ của quy hoạch sử dụng đất là tổng hợp và cân đối để xác định chỉ tiêu sử dụng đất phân bổ cho đơn vị hành chính cấp dưới chiếm ưu thế nổi trội. Quy hoạch, kế hoạch sử dụng đất quan tâm nhiều hơn đến chỉ tiêu sử dụng đất mang tính định lượng, thiếu những luận cứ xác đáng cho việc xác định nhu cầu sử dụng đất. Điều này ảnh hưởng nhiều đến chất lượng và tính khả thi của quy hoạch sử dụng đất.

\section{Thực trạng và khả năng ứng dụng công nghệ trong dự báo nhu cầu sử dụng đất}

\subsection{Các phần mềm tiện ích đang đự̛̣c áp dung}

Hiện tại và trong tương lai, công nghệ thông tin đang ngày càng phát triển và khẳng định được ưu thế vượt trội trong nhiều lĩnh vực. Trong những năm gần đây, công nghệ tin học đã được ứng dụng trong công tác lập quy hoạch sử dụng đất nói chung và trong việc dự báo nhu cầu sử dụng đất nói riêng nhưng vẫn còn hạn chế, chỉ tập trung ở một số công đoạn tính toán số liệu, số hóa bản đồ mà chưa có giải pháp đồng bộ về thiết lập và khai thác CSDL đất đai phục vụ cho công tác này. Một số phần mềm tiện ích được sử dụng phổ biến để giải hoặc hỗ trợ giải bài toán như phần mềm EXCEL với mô-đun SOLVER EXCEL; phần mềm LINGO; mô hình toán học GAMS; phần mềm MULTIOPT. Ngoài ra còn có một số phần mềm có tính chuyên dụng cao hơn để giải bài toán quy hoạch tuyến tính như XPRESS, RST2ANU, PRELIME...

Trong những năm gần đầy còn có một số phần mềm chuyên dụng đã được nghiên cứu trên cơ sở các mô hình toán để phục vụ cho việc quy hoạch sử dụng đất nông nghiệp. Mặc dù khả 
năng ứng dụng của các phần mềm đó tuy chưa cao nhưng đáng được ghi nhận như:

- Phần mềm VPLAN của Viện Khoa học Đo đạc Bản đồ (Viện Nghiên cứu Địa chính trước đây): VPLAN có khả năng kết hợp quản lý cả dữ liệu không gian và dữ liệu thuộc tính, có khả năng hỗ trợ thiết kế bản đồ quy hoạch và chức năng thống kê, tính toán, truy xuất các bảng biểu theo quy định.

- Phần mềm lập quy hoạch sư dụng đất cấp $x a \tilde{a}$ (Học Viện Nông nghiệp Việt Nam): Đây là một chương trình chạy trên dữ liệu bản đồ làm từ phần mềm MapInfo và dữ liệu thu thập của địa phương để phục vụ tạo ra bài toán quy hoạch tối ưu đa mục tiêu trên cơ sở đánh giá thích nghi đất đai và điều tra hiệu quả của các loại hình sử dụng đất.

- Phần mềm SALUP giải quyết bài toán bố trí không gian sử dụng đất đáp ứng yêu cầu đặc thù ở Việt Nam mà các phần mềm hiện có trên thế giới không giải quyết được. SALUP tương tác trực tiếp với người ra quyết định (nhà quản lý, nhà quy hoạch), trong đó các quan điểm phát triển của địa phương cũng như mong muốn của chính quyền và các đối tượng sử dụng đất được đưa vào mô hình thông qua thay đổi mức độ ưu tiên các mục tiêu. SALUP là công cụ thật sự hữu ích trong công tác lập quy hoạch sử dụng đất nông nghiệp[2].

\subsection{Khả năng ứng dụng GIS trong dụ báo nhu cầu sủ dụng đất}

Ở Việt Nam, trong xu thế hội nhập khu vực và quốc tế hiện nay, việc nghiên cứu ứng dụng và đẩy mạnh công nghệ GIS (hệ thống thông tin địa lý) như là một tất yếu khách quan. Từ chỗ các ứng dụng và phát triển chỉ mang tính tự phát, hiện nay, công nghệ GIS đã được nghiên cứu và ứng dụng rộng rãi trên nhiều lĩnh vực khác nhau, vấn đề ứng dụng GIS trong quy hoạch sử dụng đất cũng đã bắt đầu được một số nhà khoa học quan tâm trong những năm gần đây. Một trong những điểm rất mạnh của phương pháp bản đồ và GIS là chức năng phân tích không gian. Chồng xếp bản đồ là một khả năng ưu việt của GIS trong việc phân tích các dữ liệu không gian để có thể xây dựng một bản đồ mới mang các đặc tính hoàn toàn khác với bản đồ ban đầu. Khả năng ứng dụng GIS đã thể hiện trong những nghiên cứu như:

- Úng dụng GIS kết hợp với kỹ thuật đa tiêu chuẩn $M C A / A H P$ : Úng dụng phân tích thứ bậc trong ra quyết định nhóm MCA/AHP để xác định trọng số các yếu tố bền vững trong sử dụng đất, công nghệ GIS để xây dựng CSDL đất đai, phân tích không gian, biểu diễn kết quả dự báo.

- Mô hình CLUE: Mô hình này cho phép mô phỏng các lựa chọn chuyển đổi mục đích sử dụng đất và ảnh hưởng của sự chuyển đổi này. Mô hình này có 3 phiên bản chính gồm phiên bản CLUE-CR do Tom Veldkamp và Louise Fresco xây dựng, phiên bản CLUE do Peter Verburg, Kasper Kok, Free de Koning và Tom Veldkamp xây dựng và phiên bản CLUE-s: được xây dựng bởi Peter Verburg.

- Mô hình CLUE - S: Mô hình này có thể được ứng dụng trong phân tích kịch bản và mô phỏng xu hướng thay đổi sử dụng đất. Có khả năng đánh giá tác động của những thay đổi ở cấp vùng đối với cấp địa phương. Các chính sách quy hoạch được phản ánh thông qua việc gán trọng số cho các yếu tố vật lý. Tuy nhiên mô hình còn có nhiều hạn chế: không thể mô phỏng các động lực sử dụng đất ở những vùng không có lịch sử thay đổi sử dụng đất; Phụ thuộc nhiều vào phân tích hồi quy thống kê trước khi chạy mô hình; Khó khăn trong việc phân loại dữ liệu sử dụng đất hiện thời; Hạn chế của các ô dữ liệu trong việc thể hiện các khía cạnh về sự tăng trưởng xanh/thông minh ở vùng đô thị vì mỗi ô dữ liệu chỉ có thể thể hiện một giá trị/loại.

- Mô hình CLUE - SD: có điểm mạnh nội trội như đảm bảo kết quả mô hình mang tính chính xác hơn khi phân tích các yếu tố về phát triển công nghệ, nhân khẩu học, kinh tế vĩ mô, thay đổi về cung-cầu ảnh hưởng đến sử dụng đất ở 
một vùng cụ thể vì có sự kết hợp với mô hình động lực hệ thống (system dynamic model) để phân tích các động lực thay đổi sử dụng đất. Tuy nhiên do đây là mô hình tích hợp nên yêu cầu nguồn dữ liệu đầu vào của mô hình đòi hỏi chi tiết về kinh tế, nhân khẩu học, công nghệ, thị trường.

- Mô hình CA - Markov: Những thay đổi sử dụng đất theo thời gian được tính toán, dự báo trong chuỗi Markov dựa trên các ma trận chuyển đổi; trong khi, các thay đổi về mặt không gian được xây dựng trong bản đồ chuyển đổi, dựa trên phân tích đặc điểm của các khu vực lân cận và các quy tắc chuyển đổi sử dụng đất cài đặt trong quá trình chạy mô hình $\mathrm{CA}$.

- Úng dụng GIS và viến thám trong dụ báo thay đổi sử dụng đất: Với chi phí thấp, cho kết quả nhanh chóng, thu thập được dữ liệu ở những khu vực con người không thể tiếp cận; Quan sát được các hiện tượng ở phạm vi nhỏ mà mắt thường không thể quan sát; Dễ thao tác trên máy tính và kết hợp với bản đồ địa lý khác trong GIS. Tuy nhiên mô hình này không mang tính đại diện cho hiện tượng và cần được hiệu chỉnh so với thực tế; Hình ảnh cần được điều chỉnh về mặt hình học và tham chiếu địa lý để có thể sử dụng thành bản đồ; Có thể có lỗi phân loại vì cảm biến không thể phân biệt được tính chất của hình ảnh; Độ phân giải của ảnh vệ tinh không đủ chi tiết để thành lập bản đồ cho những khu vực có phạm vi nhỏ [6].

\section{Tồn tại, hạn chế trong công tác dự báo nhu cầu sử dụng đất}

Dự báo nhu cầu sử dụng đất tuy đã cơ bản đáp ứng cho việc lập các phương án quy hoạch sử dụng đất trong những năm qua được kịp thời, đạt những hiệu quả kinh tế - xã hội nhất định. Tuy nhiên, việc dự báo nhu cầu sử dụng đất còn một số hạn chế:

- Về phuoong pháp dụ báo nhu cầu sủ dụng đất: Phương pháp dự báo nhu cầu sử dụng đất chủ yếu là tính toán thủ công dựa vào các số liệu về điều kiện và yêu cầu phát triển của từng ngành và phát triển tổng hợp kinh tế - xã hội. Chưa có các phương pháp, mô hình tính toán tổng hợp một cách đầy đủ, toàn diện, khoa học và tin cậy.

- Chất lượng dụ báo nhu cầu sủ dụng đất còn hạn chế: Việc dự báo nhu cầu sử dụng đất của từng ngành chủ yếu dựa trên các yêu cầu và điều kiện chính, đôi khi còn mang tính chủ quan, chưa được tính toán cụ thể, chi tiết mà chưa căn cứ đầy đủ các yếu tố ảnh hưởng đến nhu cầu sử dụng đất; các số liệu, dữ liệu được sử dụng để tính toán xử lý chưa đầy đủ. Vì vậy chất lượng dự báo phần nào còn hạn chế, chưa sát với yêu cầu thực tế của các ngành, chưa phù hợp với các điều kiện chung, nhất là điều kiện về quỹ đất của địa phương lập quy hoạch.

- Chura có nhũng quy địh cu thể của pháp luật đối với việc dụ báo nhu cầu sủ dụng đất: Hiện nay, dự báo nhu cầu sử dụng đất mới chỉ được đề cấp đến như là căn cứ để lập quy hoạch sử dụng đất và quy định trách nhiệm của cơ quan có thẩm quyền xác định nhu cầu sử dụng đất khi lập quy hoạch sử dụng đất các cấp. Hệ thống lý luận, tiêu chuẩn kỹ thuật và cơ sở khoa học còn chưa được hoàn chỉnh, chưa tạo nền tảng vững chắc trong quá trình triển khai thực hiện.

- Năng lực cán bộ làm công tác dụ báo nhu cầu sủ dụng đất còn yếu kém, đầu tu cho việc lạp dụ báo chura được quan tâm ở nhiều địa phương: Trình độ, năng lực của đội ngũ cán bộ chuyên môn về dự báo còn thiếu và có nhiều hạn chế. Các điều kiện về vật chất cho công tác dự báo chưa đảm bảo, hầu hết các địa phương chưa bố trí thoả đáng kinh phí tạo điều kiện triển khai nhanh và đảm bảo chất lượng dự báo. Bên cạnh đó đội ngũ cán bộ được đào tạo, phát triển qua nhiều giai đoạn khác nhau và trong các điều kiện khác nhau nên trình độ không đồng đều, đặc biệt còn hạn chế trong việc ứng dụng công nghệ mới. Đây là một khó khăn rất lớn trong việc triển khai ứng dụng công nghệ trong công tác dự báo nhu cầu sử dụng đất cũng như trong công tác quản lý 
đất đai.

- Nguồn CSDL phục vu công tác dụ báo còn chura đồng bộ, thống nhất: Đất đai thường xuyên biến động, việc dự báo nhu cầu sử dụng đất phải dựa trên rất nhiều chỉ tiêu: số dân và mật độ dân số, trình độ phát triển kinh tế- xã hội, điều kiện cơ sở hạ tầng (giao thông, cấp điện, nước....), tính lịch sử, đặc điểm các tụ điểm dân cư, các điều kiện địa hình, địa chất, thủy văn, tài nguyên thiên nhiên... Nguồn số liệu đầu vào để làm cơ sở dự báo nhu cầu sử dụng đất tại các cơ quan trung ương và địa phương cũng rất khác nhau do lập ở các thời điểm khác nhau (mốc thời gian khác nhau) ảnh hưởng đến kết quả dự báo. Quá trình thống kê, kiểm kê tại các địa phương không tránh khỏi sai sót về diện tích các loại đất do đó cũng ảnh hưởng đến kết quả dự báo nhu cầu sử dụng đất.

- Khó khăn trong việc tiếp cận sủ dụng các phần mềm: Thông thường, chi phí mua phần mềm chạy mô hình không nhỏ. Bên cạnh đó, hạn chế về năng lực sử dụng mô hình (kỹ thuật và con người) ở Việt Nam cũng là một rào cản trong việc ứng dụng mô hình dự báo tài nguyên, môi trường.

\section{Những vấn đề cần đổi mới khi dự báo} nhu cầu sử dụng đất và ứng dụng công nghệ trong dự báo nhu cầu sử dụng đất

Trong thời gian tới, công tác dự báo nhu cầu sử dụng đất và ứng dụng công nghệ trong dự báo nhu cầu sử dụng đất cần có những đổi mới sau:

- Xây dưng các quy định, huớng dẫn cu thể trong các văn bản quy phạm pháp luật về dụ báo nhu cầu sủ dụng đất: Để công tác dự báo nhu cầu sử dụng đất đạt chất lượng, hiệu quả cao thì trong thời gian tới cần sớm xây dựng và ban hành những quy định, hướng dẫn cụ thể liên quan như phương pháp dự báo, các quy định kỹ thuật, trách nhiệm và trò của các cơ quan dự báo, nghiên cứu ban hành định mức sử dụng đất phù hợp với tình hình thực tiễn hiện nay....

- Lựa chon phương pháp dụ báo và xây dựng mô hình dụ báo nhu cầu sủ dụng đất phù hơp với tình hình thưc tiễn của Việt Nam: Căn cứ vào mục tiêu, yêu cầu của dự báo nhu cầu sử dụng đất thì cần lựa chọn các phương pháp dự báo phù hợp, mang tính thực tiễn cao (kết quả dự báo đạt độ chính xác mà thực tế chấp nhận được). Quy mô phát triển sử dụng các loại đất phải được thể hiện vị trí trên bản đồ. Diện tích các loại đất nên tính theo tỷ lệ chiếm dụng hợp lý, hài hòa so với diện tích đất đai tự nhiên đối với từng vùng, từng khu vực. Kết quả dự báo phải kèm theo các phụ lục giải trình những căn cứ dự báo như: quy hoạch tổng thể của vùng, quy hoạch đô thị,..., phương pháp dự báo được sử dụng, phân tích kết quả dự báo, đánh giá tính hợp lý và tính khả thi của kết quả...

- Đổi mới và úng dụng các công nghệ tiên tiến trong dụ báo nhu cầu sủ dụng đất: Ứng dụng công nghệ trong dự báo nhu cầu sử dụng đất sẽ đạt được những mục tiêu sau: Đảm bảo tính đầy đủ, khách quan khi tổng hợp, cân đối nhu cầu sử dụng đất của các ngành, lĩnh vực; Cân đối giữa nhu cầu và khả năng đáp ứng nguồn lực tài nguyên đất của địa phương; Cung cấp số liệu khi lập và điều chỉnh quy hoạch sử dụng đất. Nhằm nâng cao chất lượng và hiệu quả của công tác dự báo nhu cầu sử dụng đất hiện nay thì việc ứng dụng công nghệ trong tính toán số liệu cũng như thể hiện vị trí không gian là rất cần thiết. Do đó cần xây dựng phần mềm hỗ trợ tính toán nhu cầu sử dụng đất cũng như ứng dụng GIS và các phần mềm chuyên dụng để xác định vị trí không gian sử dụng đất.

Để làm được điều đó, trong thời gian tới, rất cần một lộ trình hiệu quả để đẩy nhanh việc ứng dụng công nghệ trong dự báo nhu cầu sử dụng đất để góp phần đổi mới toàn diện và nâng cao hiệu quả thực tiễn trong công tác quy hoạch sử dụng đất:

- Xây dựng lộ trình hoàn thiện hệ thống CSDL bao gồm các lĩnh vực chuyên ngành và đa ngành, làm cơ sở đầu vào cho công tác dự báo lập quy hoạch - chia sẻ thông tin - quản lý sau 
quy hoạch. Đây là điều kiện cần thiết và quan trọng nhất để có thể tạo nên hệ thống số liệu bao quát đầy đủ các yếu tố phục vụ công tác dự báo nhu cầu sử dụng đất.

- Đẩy mạnh đào tạo nguồn nhân lực, đặc biệt tập trung và đội ngũ cán bộ những người trực tiếp tham gia công tác dự báo.

- Sớm có lộ trình nghiên cứu và triển khai hạ tầng công nghệ thông tin để có thể đáp ứng các nhu cầu lưu trữ, truy cập, tra cứu, khai thác thông tin phục vụ công tác dự báo và quản lý đất đai.

\section{Kết luận}

Qua việc nghiên cứu và phân tích thực trạng dự báo nhu cầu sử dụng đất cho thấy vấn đề cần thiết hiện này là cần nghiên cứu ứng dụng công nghệ và xây dựng mô hình phù hợp nhằm dự báo nhu cầu sử dụng đất bảo đảm tính khách quan và hiệu quả, qua đó bảo đảm tính khả thi và hiệu quả của quy hoạch sử dụng đất.

\section{Tài liệu tham khảo}

[1]. Võ Tử Can (2001). Phương pháp luận co bản về Quy hoạch sủ dụng đất đai. Dư án 3 Quy hoạch sủ dụng đất đai thuộc chuoong trình hơp tác Việt Nam Thuy Điển về Đổi mới hệ thống địa chính.
[2]. Lê Cảnh Định và Trần Trọng Đức (2011). Tích hợp GIS và phân tích quyết định nhóm đa muc tiêu mò̀ trong quy hoạch sử dụng đất nông nghiẹp.

[3]. Nguyễn Quang Học (2011). Xây dụng phần mềm quy trình công nghệ lập quy hoạch sủ dụng đất cấp xã.

[4]. Hà Minh Hòa (2009). Áp dụng các phưong pháp và công nghệ mói trong công tác quy hoạch sủ dụng đất ở nước ta.

[5]. Nguyễn Minh Khoa (2016). Nghiên cưu kinh nghiệm quốc tế về ưng dụng mô hình hóa trong dụ báo biến động tài nguyên và môi trường để đura ra các phương án đề xuất, đề tài nghiên cúu mức độ cao hơn, phù hợp thực tiễn của Việt Nam.

[6]. Nguyễn Sỹ Linh (2010). Tổng quan về phưong pháp dụ báo và khả năng áp dụng một số mô hình trong dư báo biến động tài nguyên và môi trường tại Việt Nam.

[7]. Trần Xuân Miễn (2016). Nghiên cưu nhu cầu sư dụng đất phục vu xây dựng nông thôn móri trên địa bàn huyện Yên Dũng, tỉnh Bắc Giang.

[8]. Nguyễn Dũng Tiến (2009). Nghiên cưu thưc trạng và giải pháp hoàn thiện hệ thống quy hoạch sư dụng đất đai trong thờ kỳ công nghiẹp hóa. $\bigcirc$

\section{Summary}

\section{Current situation and technology application in forecasting land use demand}

Vu Thi Minh Hue

Dao Thi Ha Thanh

Vu Thi Hong

Nguyen Van Hau

General department of land administration

This paper introduces the current situation of forecasting land use demand and the ability to apply technology in forecasting land use demand, thus we propose some issues that need to be renewed when forecasting land use demand in order to improve the quality of forecasting, improve the orientation, the forecast of land use planning to ensure the effectiveness and feasibility. $\bigcirc$ 